with redundant information (the new Chambers Universal Learners' Dictionary is a notable exception). Will a foreign scientist or student really be helped by seeing An or $\mathrm{H}$ against a word? Even if he looks in the front matter, where he will learn that the former denotes a non- gradable antonym and the latter a hyponym, will he be any the wiser? If I were a foreign scientist I would want a dictionary that tells me what I want to know simply, by having the information available in its alphabetical place. I am not sure that I would want to be confused with coded answers to questions that I am never likely to ask. Hyponym indeed!

Alan Isaacs, a former teacher of scientific English to foreign students, is editor of the Penguin Dictionary of Science and Longman's New Dictionary of Physics, and science editor of Collins English Dictionary.

\section{RNP particles and the virus club}

\section{B.S. Cox}

Viruses and Plasmids in Fungi. Edited by

Paul A. Lemke. Pp.680. (Dekker: 1979.) SFr.110, \$55.

MANY fungi harbour ribonucleoprotein particles consisting of a spherical or polyhedral capsid-like structure $35 \pm 10 \mathrm{~nm}$ in diameter, containing one or more molecules of double-stranded RNA. The particles are rather reminiscent of reovirus.

They are a remarkable group of objects. In the first place, it appears to be quite impossible to infect any fungus with them. The lengths to which numbers of mycovirologists have gone to demonstrate this rather fundamental property of a virus have been extraordinary, both for the manhours spent and the total lack of success. Secondly, without exception, they are symptomless. Of course it is rather difficult to connect the symptoms of a disease with a virus if one cannot infect the host with it; and the energetically-researched "La France disease" of cultivated mushrooms may indeed be caused by the two or more 'viruses' associated with it. On the other hand, of course, the disease may cause the viruses. 'Virus' is often found, apparently, in healthy mushrooms.

Not all of the $d s$ RNAs of fungi are without phenotypic effects. Cytoplasmically inherited $d s$ RNAs produce the 'killer' toxins of many species of yeast and of the smut fungus, Ustilago maydis. They also apparently cause the fascinating non-pathogenic variant of Endothia parasitica. This blight has deprived two generations of Americans of their native chestnuts for the Thanksgiving stuffing. The hypovirulence of the variant is invasive and suppressive, and can be used not only to limit the spread of the cankers caused by virulent strains on Castanea but actually to depress the virulence of the pathogen itself.

Cryptic or not, these RNP particles of fungi are curiosities. They are extremely widespread, occurring in all major groups of fungus including water moulds. They form a strikingly homogeneous group of

\section{Jewish genetics}

\section{Kurt Hirschhorn}

Genetic Disorders among the Jewish People. By R.M. Goodman. Pp.493. (Johns Hopkins University Press: 1979.) $\$ 32.50, £ 17.50$.

THE genetics of the Jewish people have received a great deal of attention over the past few years. This is primarily due to the virtually unequalled opportunity created by the population dynamics of the state of Israel. Previously isolated groups of Jews have been immigrating to Israel, where they continue a certain degree of inbreeding and are beginning to outbreed with other Jewish groups. Driven by the tradition of Israeli research on human genetics, particularly under the leadership of the late Drs E. Goldschmidt and C. Sheba, a new and large generation of human geneticists has been quick to take advantage of this temporary opportunity.

Three recent publications summarizing these data as well as studies done outside Israel have been The Genetics of the Jews by A.E. Mourant, A.C. Kopec and K. Domaniewska-Sobczak (Clarendon:
1978), Genetic Diseases Among Ashkenazi Jews edited by R.M. Goodman and A.G. Motulsky (Raven: 1979) and the book reviewed here. The first of these is primarily a tabular accumulation of gene frequencies in various Jewish groups and contains much useful data, while the second represents the proceedings of a symposium with many excellent reviews.

This present book is a tour de force which pulls together a mass of reports and develops a comprehensive description of the status of these studies. One could argue with some details such as interpretations of ancient history and the inclusion of a number of genetic diseases found in Jews with "Jewish genetic diseases", and there are occasional lapses in clarity. None of these criticisms should detract from the fact that this is a major and useful book for all human geneticists as well as students of Judaism. This is a field which is applicable to genetic centres wherever Jewish patients may appear and which is certain to grow over the next 20 years. The book also provides a general model for genetic studies in populations, and is therefore recommended for a wide audience.

Kurt Hirschhorn is Professor and Chairman of the Department of Pediatrics at Mount Sinai Medical Center, New York. organelles. Homogeneity, universality and non-infectionness suggest a very ancient common origin, but how have they been maintained? Is it possible for a nonessential, wholly cryptic self-replicating particle to survive in such a specialized environment without the means of spreading by infection? The killer (M) $d s$ RNA of yeast depends for its maintenance on 30 nuclear genes: one mutation and it's gone. How does it survive? The L-dsRNA has not been found to depend on any nuclear genes. Why not? Do the $d s$ RNAs do something useful, or is the killer/immunity property a selfselecting mechanism? If so, do all fungi possess it?

Although neither answers to these questions nor, indeed, the questions, are to be found in this book, there are two clear and succinct reviews of the genetics and molecular biology of the RNP particles of yeast, Ustilago and Endothia. There are also excellent accounts, sometimes commendably brief, of an assortment of non-RNP particles, DNA plasmids, bacterial or rickettsia-like structures and even a couple of cytoplasmically-inherited conditions with no particle to call their own (senescence in Podospora and meiotic failure in Coprinus). For the rest, there are detailed, rather self-indulgent articles cataloguing biophysical and ultrastructural studies of RNPs, speculations about their life-histories, a methods paper without protocols, many more or less indistinguishable electron micrographs and many a discussion about what these RNPs should be called. The general opinion is that they should be awarded the accolade 'virus', perhaps by broadening the category of admissible members. I can't help feeling that this obsession with joining the club has rather diverted attention and effort away from the problem of what they really are. Much of the repetitive material about functionless particles could have been condensed into a single review article (Chapter II covers all the ground) and perhaps some space given to the many other cytoplasmically-inherited determinants of fungi which have phenotypes but no physical basis yet identified. Visibility in the electron microscope is not the only passport to respectability.

The book is a little out of date but is, nevertheless, for some topics, a very useful source.

B.S. Cox is a Lecturer in Botany at Oxford University. 